\title{
Slag-metal Separation and Reduction Behaviors of Vanadium- bearing Titanomagnetite Metallized Pellets
}

\author{
Jianjiang XIN, Nan WANG, ${ }^{*}$ Min CHEN and Chen CHEN \\ School of Metallurgy, Northeastern University, Shenyang, Liaoning Province, 110819 China. \\ (Received on August 20, 2019; accepted on October 29, 2019)
}

\begin{abstract}
Vanadium oxides in metallized pellets can be reduced into metal phase by carbothermal reduction reaction in electric furnace smelting process. Smelting-separation parameters have an important influence on slag-metal separation and reduction behaviors of vanadium oxides. The effects of smelting temperature, slag basicity and smelting time on slag-metal separation, the mass fractions of $V$ and $C$ in metal phase and recovery degree of $\mathrm{V}$ for vanadium-bearing titanomagnetite metallized pellets were investigated in the present work. The results demonstrate that the increase of smelting temperature promotes the reduction of vanadium oxides, resulting in an increases of the mass fraction and recovery degree of $\mathrm{V}$, whereas the mass fraction of $\mathrm{C}$ decreases continuously. Within proper slag basicity and smelting time ranges, increasing basicity and time is beneficial to the coalescence and settlement of metallic iron droplets and reduction of vanadium oxides in smelting separation process. The mass fraction and recovery degree of $\mathrm{V}$ increases firstly and then decreases with the increment of slag basicity and smelting time, whereas the mass fraction of $C$ initially decreases and subsequently increases, showing an opposite tendency with that of V. Under the optimal conditions, smelting temperature of $1450^{\circ} \mathrm{C}$, slag basicity of 0.7 and smelting time of 40 min, the recovery degree of $\mathrm{V}$ could reach the highest of $99.8 \%$, and the mass fraction of $\mathrm{V}$ and $\mathrm{C}$ are $0.27 \%$ and $1.2 \%$, respectively.
\end{abstract}

KEY WORDS: vanadium-bearing titanomagnetite; metallized pellets; smelting-separation; reduction.

\section{Introduction}

Vanadium-bearing titanomagnetite ore is an important mineral resource containing vanadium, titanium and iron. It is widely distributed around the world mainly including China, Russia, American and North Africa. ${ }^{1,2)}$ Especially in the Panxi region of China, the proven deposits account for more than $90 \%$ of total reserves in China., ${ }^{3,4)}$ At present, the blast furnace (BF) process is widely used by most countries to produce hot metal containing vanadium and titanium-bearing blast furnace slag. ${ }^{5-9)}$ However, BF process needs consume a large amount of expensive coke, and tends to have a low recovery of $\mathrm{V}$ less than $50 \%$, resulting in a serious loss of valuable elements. ${ }^{5,10)}$ Therefore, as an alternative route of conventional BF process, direct reduction with subsequent smelting-separation of metallized pellet in electric furnace has gained increasing attention to increase the utilization level of valuable elements. Zheng ${ }^{11)}$ performed researches on the coal-based direct reduction of vanadium-titanium magnetite by using rotary kiln-electric furnace and found that the metallization rate showed a remarkable increase within the low reduction temperature, reduction time and carbon amount ranges. Sheng et al. ${ }^{12)}$ examined the effects of $\mathrm{n}(\mathrm{C}) / \mathrm{n}(\mathrm{Fe})$ ratio $(0.1-1.2)$ and temperature $\left(1000-1250^{\circ} \mathrm{C}\right)$ on the

\footnotetext{
* Corresponding author: E-mail: wangn@smm.neu.edu.cn DOI: https://doi.org/10.2355/isijinternational.ISIJINT-2019-529
}

behaviors of vanadium and chromium during coal-based direct reduction and magnetic separation, and the recovery ratios of $\mathrm{V}, \mathrm{Cr}$ and $\mathrm{Ti}$ were only about $45.3 \%, 76.0 \%$ and $20 \%$, respectively. The effects of magnetic intensity, reduction temperature, reduction time, carbon ratio, and coal particle size on the efficiency of direct reduction and magnetic separation were investigated by Chen et al., ${ }^{13)}$ and the recovery of $\mathrm{V}$ was concluded to be $75 \%$. Wu et $a l .{ }^{14)}$ investigated the influences of smelting temperature (1 500-1 $\left.575^{\circ} \mathrm{C}\right)$, smelting time $(15-60 \mathrm{~min})$ and the basicity of metallized pellet $(0.1-1.2)$ on vanadium and iron recovery. The results showed that $90.17 \%$ vanadium and $92.98 \%$ iron in the metallized pellet could be recovered and the $\mathrm{TiO}_{2}$ grade in titanium slag could reach $55.01 \%$. Tang et $a l .{ }^{15)}$ studied the slag-metal separation behavior of highchromium vanadium-bearing titanomagnetite metallized pellet obtained from gas-based direct reduction. ${ }^{16)}$ With the optimized parameters (melting temperature: $1625^{\circ} \mathrm{C}$, melting time: $40-50 \mathrm{~min}$, additive $\mathrm{CaF}_{2}: 2 \%$ and basicity: 1.1 ), the recovery ratios of $\mathrm{Fe}, \mathrm{V}$ and $\mathrm{Cr}$ could reach around $99 \%, 97 \%$ and $92 \%$, respectively.

So far, most of the research works are mainly focused on the direct reduction of vanadium-bearing titanomagnetite ore and less attention is paid to the smelting-separation and further reduction behavior of metallized pellets and relevant mechanisms. Moreover, few researches on the variation of carbon content in the metal phase after smelting-separation have been reported, which is important for the vanadium- 
extracting from hot metal. Therefore, it is necessary to investigate the slag-metal separation and reduction behaviors of metallized pellets during smelting process. In the present work, the effects of smelting parameters including smelting temperature, slag basicity and smelting time on the slag-metal separation of metallized pellets, the contents of $\mathrm{V}$ and $\mathrm{C}$ in metal phase and recovery degree of $\mathrm{V}$ were studied, and relevant mechanisms were discussed.

\section{Experimental}

\subsection{Raw Materials}

The metallized pellets produced by the coal-based direct reduction were supplied by a steel plant in China. The typical chemical composition and XRD analysis results are listed in Table $\mathbf{1}$ and Fig. 1, and the metallization degree and original basicity of the metallized pellets are $73 \%$ and 0.1 , respectively. Besides, the metallized pellet contains $7.01 \%$ carbon used for further reduction of iron and vanadium oxides and carburization during the smeltingseparation process. The main phases in the metallized pellet are $\mathrm{Fe}, \mathrm{Fe}_{3} \mathrm{O}_{4}, \mathrm{Fe}_{2} \mathrm{O}_{3}, \mathrm{FeTiO}_{3}, \mathrm{FeV}_{2} \mathrm{O}_{4}$ and $\mathrm{C}$. In addition, an amorphous phase containing silicate presented in the pellet is also observed from XRD pattern. Figure 2 presents the scanning electron microscopy (SEM) and energy dispersive spectroscopy (EDS) results of the metallized pellet running at $20 \mathrm{kV}$ (Ultra Plus, Zeiss Germany), indicating that the white phase (point A) is metallic iron whereas the dark gray phase (point $\mathrm{B}$ ) is complex silicate mineral with $\mathrm{V}$ and $\mathrm{Ti}$ elements distributing in the slag phase.

\subsection{Experimental Procedure}

Before the smelting-separation experiment, the metallized pellets were crushed and ground, and then mixed with pure additive $\mathrm{CaO}$ in a certain proportion to obtain the required slag basicity $(R=0.1-1.0)$. The slag basicity in the present study was selected as binary basicity, which is defined as Eq. (1). Next, the well-mixed powder was pressed into a tablet and loaded into a corundum crucible (diameter $\times$ height: $30 \times 40 \mathrm{~mm}$ ). Then the crucible was placed into a high temperature electric resistance furnace and heated to the desired high temperature $\left(\mathrm{T}=1450-1600^{\circ} \mathrm{C}\right)$ to separate the molten metal and slag phases under high-purity argon gas flow (99.999\%). The gas flow rate was controlled by a mass flow controller and the flow rate was $2 \mathrm{~L} / \mathrm{min}$. After holding at the desired high temperature for different smelting-separation time $(\mathrm{t}=20-60 \mathrm{~min})$, the crucible was taken out rapidly and quenched in liquid argon. Finally, the contents of $\mathrm{C}$ and $\mathrm{V}$ in the metal phase were analyzed by carbon-sulfur analyzer (CS230, LECO USA) and ICP-OES (Optima 8300 DV, Perkin Elmer USA), respectively and the slag phase was analyzed by X-ray diffraction (X'Pert MPD Pro, PANalytical, Almelo, the Netherlands) using $\mathrm{Cu} \mathrm{K} \alpha$ radiation $(\lambda=1.5406 \AA)$ with a diffraction angle of $10-90^{\circ}$, step-length of $0.02^{\circ}$ and scanning rate of $2 \% \mathrm{~min}$.

$$
R=\frac{\mathrm{wt}(\mathrm{CaO})}{\mathrm{wt}\left(\mathrm{SiO}_{2}\right)}
$$

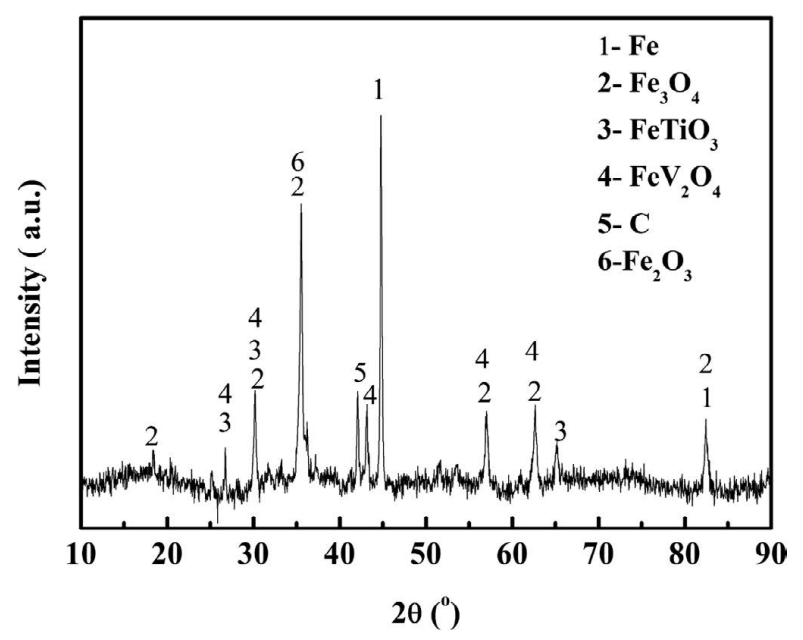

Fig. 1. XRD pattern of the metallized pellet.

Table 1. Chemical compositions of the metallized pellet (wt \%).

\begin{tabular}{cccccccccccccc}
\hline $\mathrm{TFe}$ & $\mathrm{MFe}$ & $\mathrm{Fe}_{3} \mathrm{O}_{4}$ & $\mathrm{SiO}_{2}$ & $\mathrm{CaO}$ & $\mathrm{MgO}$ & $\mathrm{Al}_{2} \mathrm{O}_{3}$ & $\mathrm{MnO}$ & $\mathrm{TiO}_{2}$ & $\mathrm{~V}_{2} \mathrm{O}_{5}$ & $\mathrm{~S}$ & $\mathrm{P}$ & $\mathrm{C}$ & Standard deviations \\
\hline 61.12 & 44.39 & 12.84 & 9.18 & 1.00 & 2.64 & 4.66 & 0.53 & 6.76 & 0.30 & 0.11 & 0.11 & 7.01 & $\leq \pm 0.3-0.5 \%$
\end{tabular}
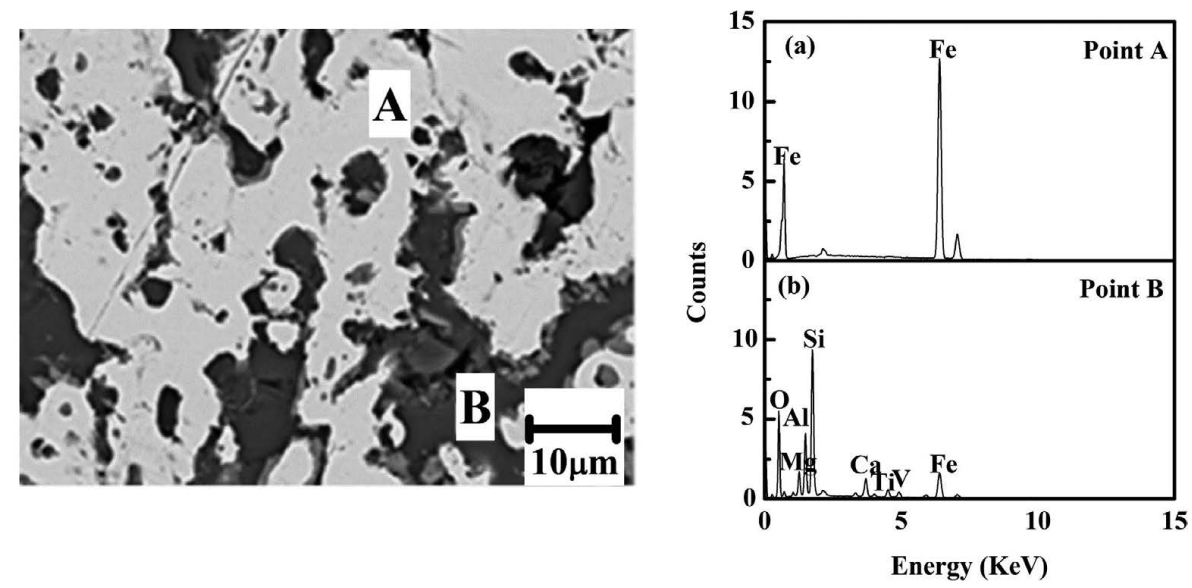

Fig. 2. SEM and EDS analysis results of the metallized pellet. 
where $w t(\mathrm{CaO})$ and $w \mathrm{t}\left(\mathrm{SiO}_{2}\right)$ are the mass fraction of $\mathrm{CaO}$ and $\mathrm{SiO}_{2}$ in the sample, respectively. The recovery degree of $\mathrm{V}$ was evaluated according to Eq. (2).

$$
\beta=\frac{w_{1} \times m_{1}}{w_{2} \times m_{2}} \times 100 \%
$$

where $\beta$ is the recovery degree of $\mathrm{V}$ after smelting separation; $w_{1}$ and $w_{2}$ are the mass fractions of $\mathrm{V}$ in the metal phase after smelting separation and metallized pellet (wt $\%$ ), respectively; $m_{1}$ and $m_{2}$ are the mass of the metal phase after smelting separation and metallized pellet (g), respectively.

\section{Results and Discussions}

\subsection{Effect of Smelting Temperature}

The influences of smelting temperature on the separation behavior between the slag and metal phases of metallized pellets were studied under the conditions of slag basicity of 1.0 and smelting time of $40 \mathrm{~min}$. Figure 3 presents the photographs of slag and metal phases under different smelting temperatures. It can be observed that the metal phase can be separated well from the slag phase in the temperature range of $1450-1600^{\circ} \mathrm{C}$, and no iron nugget is found among the slag phase, indicating that the coalescence of the metallic iron droplets during smelting-separation process is complete and the molten slag has a good fluidity.

During the smelting-separation process of metallized pellets, the generated metallic iron droplets through reduction reaction undergo coalescence and settlement processes, and the settling velocities of iron droplets inside the molten slag can be described by Stokes equation, ${ }^{17)}$ expressed by Eq. (3).

$$
v=\frac{2 g r^{2}\left(\rho_{\mathrm{m}}-\rho_{\mathrm{s}}\right)}{9 \eta}
$$

where $v$ is the settling velocity of metal droplet, $\left(\mathrm{kg} / \mathrm{m}^{3}\right)$; $\mathrm{g}$ is the gravity acceleration, $\left(\mathrm{m} / \mathrm{s}^{2}\right) ; r$ is the droplet radius, $(\mathrm{m}) ; \rho_{\mathrm{m}}$ is the iron density, $\left(\mathrm{kg} / \mathrm{m}^{3}\right) ; \rho_{\mathrm{s}}$ is the density of mol- ten slag, $\left(\mathrm{kg} / \mathrm{m}^{3}\right) ; \eta$ is the viscosity of molten slag, $(\mathrm{Pa} \cdot \mathrm{s})$. The slag-metal separation could be promoted under higher smelting temperature. Increasing smelting temperature would significantly decrease the viscosity and density of molten slag discussed in the authors' previous papers, ${ }^{18,19}$ ) which improve the fluidity of molten slag and decrease the settling resistance of the iron droplet.

The XRD spectra results of the slag phase after smeltingseparation under different smelting temperatures are shown in Fig. 4. The main phases in the slag are complex pyroxene $\left(\mathrm{Al}_{0.433} \mathrm{Ca}_{0.968} \mathrm{Fe}_{0.23} \mathrm{Mg}_{0.578} \mathrm{O}_{6} \mathrm{Si}_{1.728} \mathrm{Ti}_{0.059}\right)$, perovskite $\left(\mathrm{CaTiO}_{3}\right.$, melting point of $\left.1960^{\circ} \mathrm{C}\right)$ and magnesia-alumina spinel $\left(\mathrm{MgAl}_{2} \mathrm{O}_{4}\right.$, melting point of $\left.2250^{\circ} \mathrm{C}\right)$. With increasing smelting temperature to $1550^{\circ} \mathrm{C}$ and $1600^{\circ} \mathrm{C}$, the diffraction peaks intensity of $\mathrm{MgAl}_{2} \mathrm{O}_{4}$ increases. A slight erosion was observed by checking morphology of the corundum crucibles under $1550^{\circ} \mathrm{C}$ and $1560^{\circ} \mathrm{C}$. To determine whether there are additional chemical composition changes occurring due to this contact, the slag compositions under different temperatures were analyzed and the results showed that there is no obvious composition changes.

The effects of smelting temperature on the mass fractions of $\mathrm{V}$ and $\mathrm{C}$ in metal phase and recovery degree of $\mathrm{V}$ are presented in Fig. 5. With temperature increasing from $1450^{\circ} \mathrm{C}$ to $1600^{\circ} \mathrm{C}$, the recovery degree and mass fraction of $\mathrm{V}$ increase from $89 \%$ and 0.24 to $96 \%$ and 0.26 , respectively, while the mass fraction of $\mathrm{C}$ decreases from $1.83 \%$ to 0.59 gradually. Here, the standard Gibbs free energies of the reduction reactions at reaction interface by solid carbon in molten slag and carbon in molten iron are calculated to discuss the effect of smelting temperature, as shown in Fig. 6. It should be noted that increasing smelting temperature clearly promotes the carbon reduction reaction of iron, vanadium and titanium oxides, and $\mathrm{FeO}$ and $\mathrm{V}_{2} \mathrm{O}_{3}$ in molten slag can be more easily reduced into the molten iron by solid carbon than that of $\mathrm{TiO}_{2}$ under higher temperature conditions due to the smaller values of $\Delta G^{\theta}$. Meanwhile, the viscosity of the molten slag decreases with increasing tem-

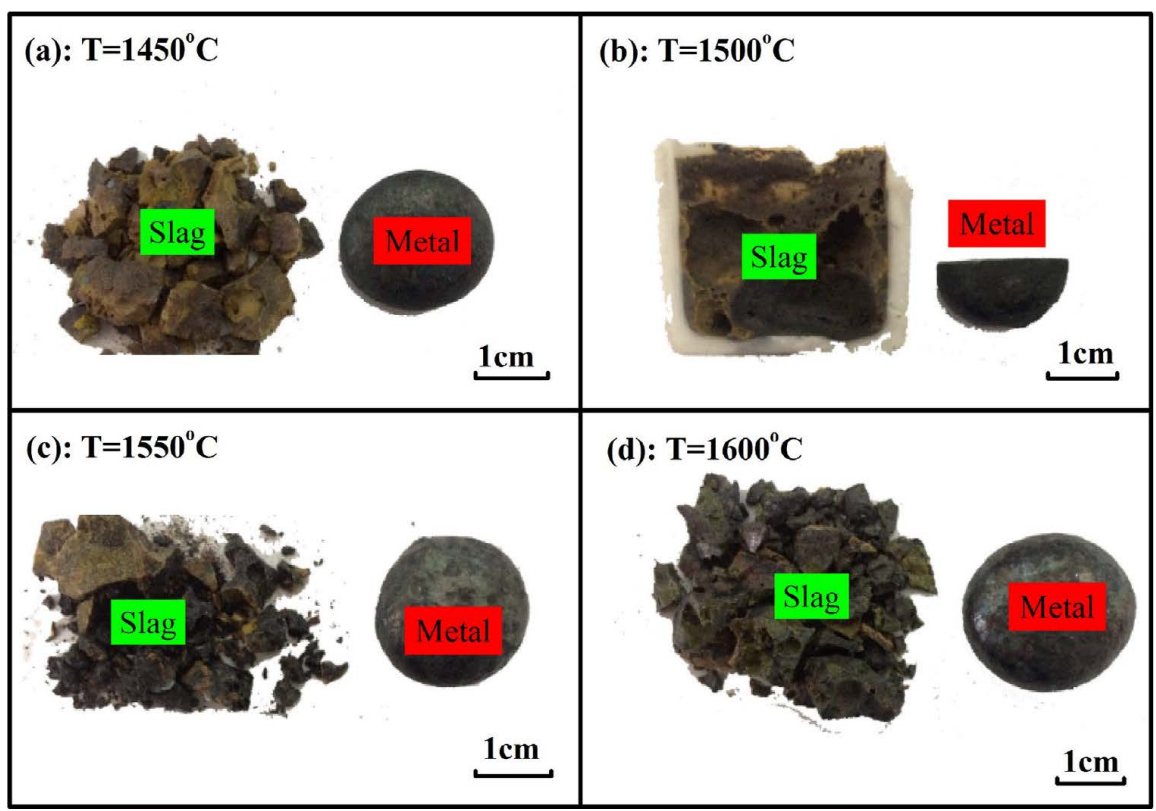

Fig. 3. Photographs of metal and slag phases after smelting-separation under different smelting temperatures. (Online version in color.) 
perature, which facilitate the melting-separation of $\mathrm{V}$ from the molten slag into the metal phase. Although it is difficult for titanium oxides are reduced by carbon in molten iron, to suppress the reduction of $\mathrm{TiO}_{2}$ by solid carbon in molten slag, the smelting temperature should be controlled below $1470^{\circ} \mathrm{C}$. Moreover, in the subsequent vanadium extraction process, the conversion temperature between carbon and vanadium is usually thought to be $1350-1400^{\circ} \mathrm{C} .^{20)}$ In view of vanadium-extracting and carbon-maintaining, lower temperature is recommended during the early smelting stage,

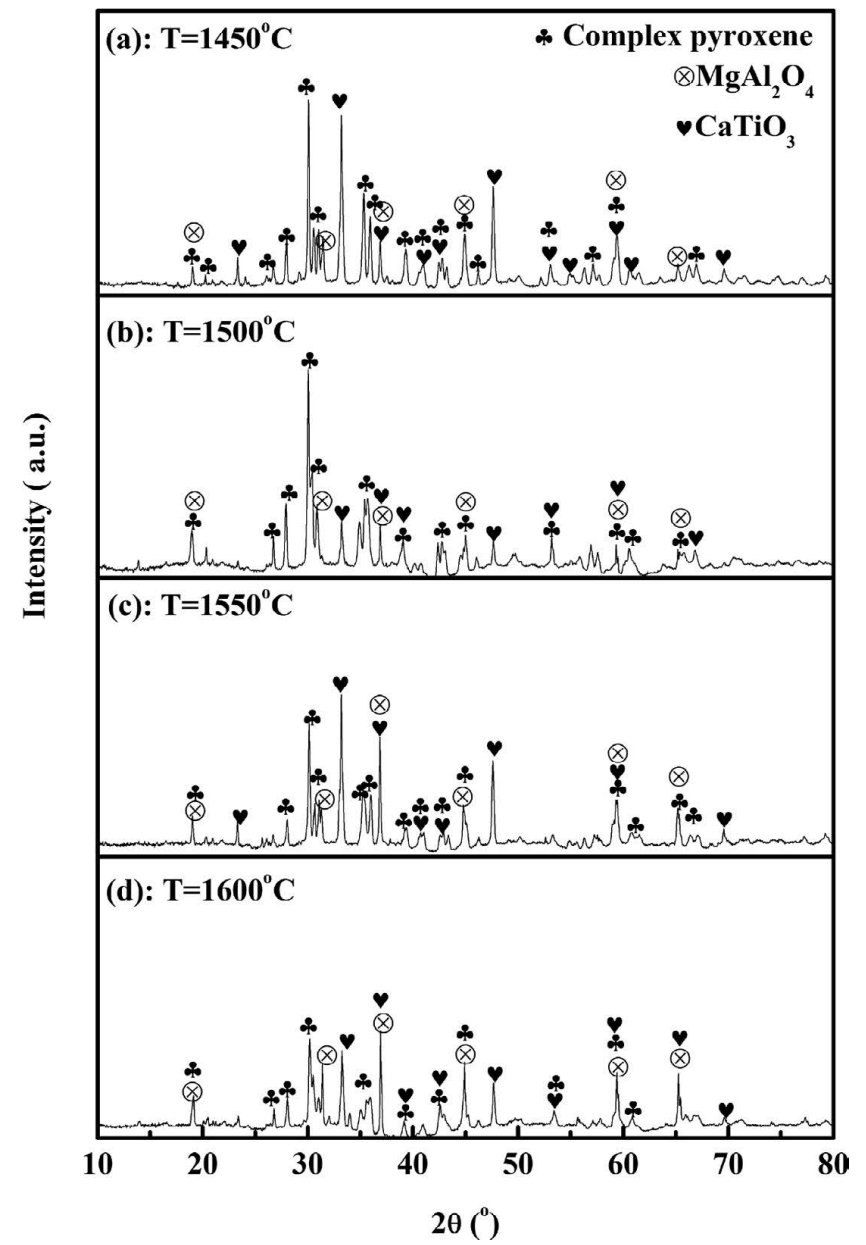

Fig. 4. XRD patterns of the slag phase after smelting-separation under different smelting temperatures.

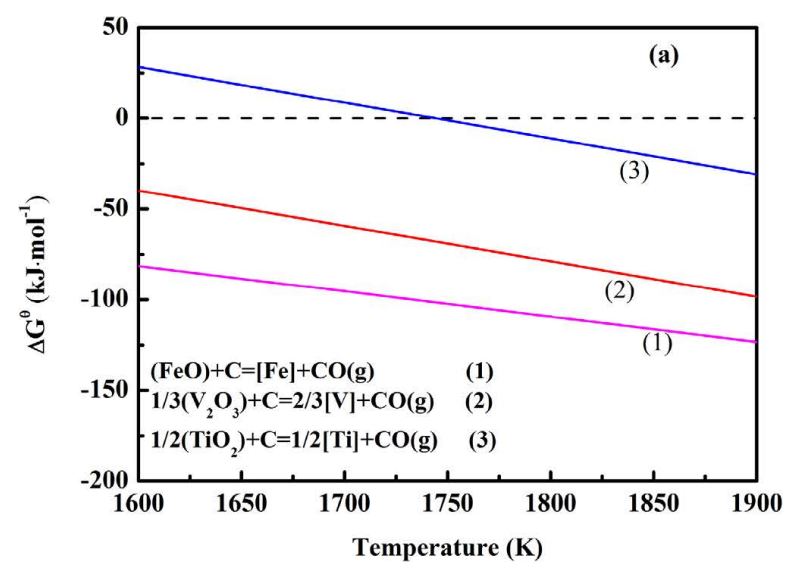

and the proper smelting temperature should be maintained at about $1450^{\circ} \mathrm{C}$.

During the smelting-separation process of metallized pellet, the reduction process of vanadium oxides consist of two stages. First, a certain amount of vanadium oxides are reduced into molten iron by solid carbon in molten slag, expressed by Eq. (4), while some solid carbons are dissolved into molten iron rapidly. Then, the vanadium oxides in molten slag would be further reduced by carbon in the molten iron, as described by Eq. (5).

$$
\begin{aligned}
& \left(\mathrm{V}_{2} \mathrm{O}_{3}\right)+3 \mathrm{C}=2[\mathrm{~V}]+3 \mathrm{CO}(\mathrm{g}) \\
& \left(\mathrm{V}_{2} \mathrm{O}_{3}\right)+3[\mathrm{C}]=2[\mathrm{~V}]+3 \mathrm{CO}(\mathrm{g})
\end{aligned}
$$

The reduction process includes the following steps in the first stage: (1) diffusion of $\mathrm{V}_{2} \mathrm{O}_{3}$ from molten slag to the solid-molten slag interface; (2) reduction reaction at the reaction interface; (3) diffusion of $\mathrm{V}$ from reaction interface to the molten metal. For the second stage, the reduction process could be described as following steps: (1) diffusion of $\mathrm{V}_{2} \mathrm{O}_{3}$ from molten slag to the slag-metal interface; (2) diffusion of carbon from molten iron to the slag-metal interface; (3) reduction reaction at the slag-metal interface; (3) diffusion of $\mathrm{V}$ from slag-metal interface to the molten metal; (4) escape of CO generated at slag-metal interface. It

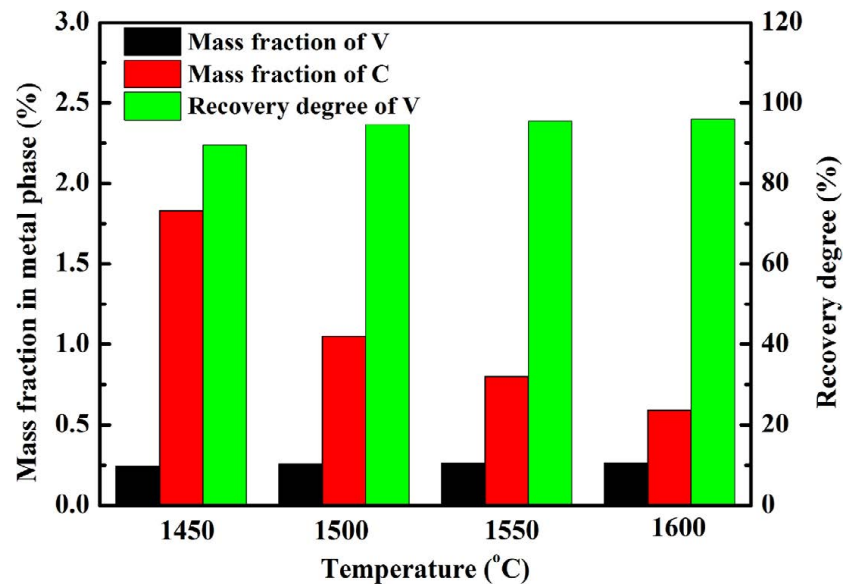

Fig. 5. Effect of smelting temperature on the contents of $\mathrm{V}$ and $\mathrm{C}$ in metal phase and recovery degree of V. (Online version in color.)

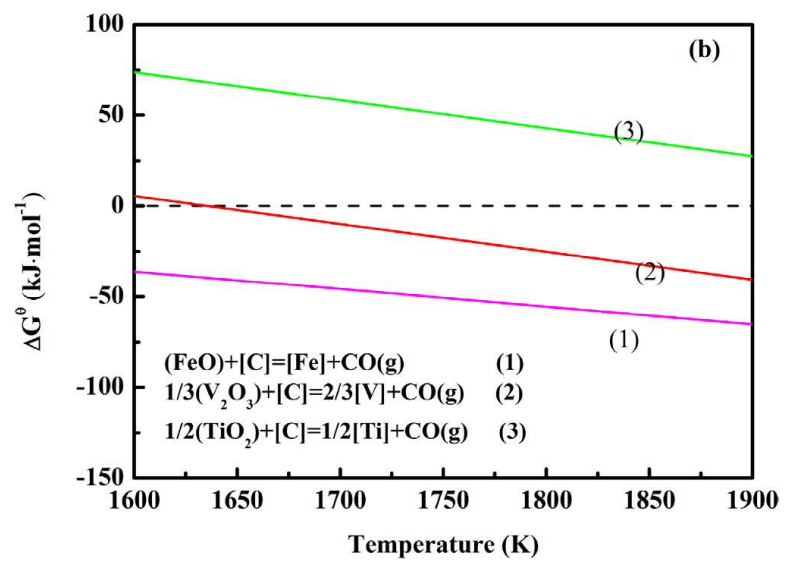

Fig. 6. Standard Gibbs free energies of the carbothermal reduction reactions at reaction interface. (Online version in color.) 
is obviously that reduction reactions and escape of $\mathrm{CO}$ are impossible to be the limiting step due to high temperature. In fact, it is usually believed that the entire reduction process is mainly controlled by the mass transfer of $\mathrm{V}_{2} \mathrm{O}_{3}$ in the molten slag or $\mathrm{V}$ in the molten iron. If the overall rate is controlled by a combination of the two steps, the reaction kinetics would be governed by a mixed mechanism.

\subsection{Effect of Slag Basicity}

Under the condition of different slag basicities, the photographs of slag and metal phases after smelting-separation at $1450^{\circ} \mathrm{C}$ for $40 \mathrm{~min}$ are shown in Fig. 7. Although effective separation of slag and metal can be achieved, a few small iron nuggets still exist in the slag with a basicity of 0.1 , as presented in Fig. 7(a). On the other hand, no iron nugget was found in the slag when the slag basicity was equal or greater than 0.4, as shown in Figs. 7(b)-7(d). It is suggested that the coalescence and settlement of metallic iron droplets are incomplete with the slag basicity of 0.1 due to the high viscosity of molten slag. With increasing the slag basicity, the slag viscosity was decreased, which the coalescence and settlement of iron droplets were accelerated in smelting separation process. Therefore, the iron nuggets in the slag finally almost vanish.

The XRD spectras of molten slag with different slag basicities are displayed in Fig. 8. It is revealed that with the slag basicities of 0.1 and 0.4 , the slag phase contains only pseudobrookite $\left(\mathrm{Fe}_{2} \mathrm{TiO}_{5}\right)$ that has not been reduced by carbon. ${ }^{21-23)}$ With the increase of slag basicity to 0.7 , the diffraction peak of $\mathrm{Fe}_{2} \mathrm{TiO}_{5}$ disappeared, and complex pyroxene and a small amount of $\mathrm{CaTiO}_{3}$ and $\mathrm{MgAl}_{2} \mathrm{O}_{4}$ were detected in slag. When the slag basicity was further increased to 1.0, the peak of $\mathrm{CaTiO}_{3}$ became stronger obviously. To verify the effect of slag basicity, the liquidus of $\mathrm{SiO}_{2}-\mathrm{CaO}-\mathrm{TiO}_{2}$ system was calculated using FactSage 7.0, as shown in Fig. 9, and the liquidus temperature of $\mathrm{SiO}_{2}-$ $\mathrm{CaO}-\mathrm{TiO}_{2}$ system decreases gradually with the slag basic- ity increasing from 0.1 to 0.7 . However, when the basicity is further increased to 1.0, the slag composition is located in $\mathrm{CaTiO}_{3}$ region and the liquidus temperature increases,

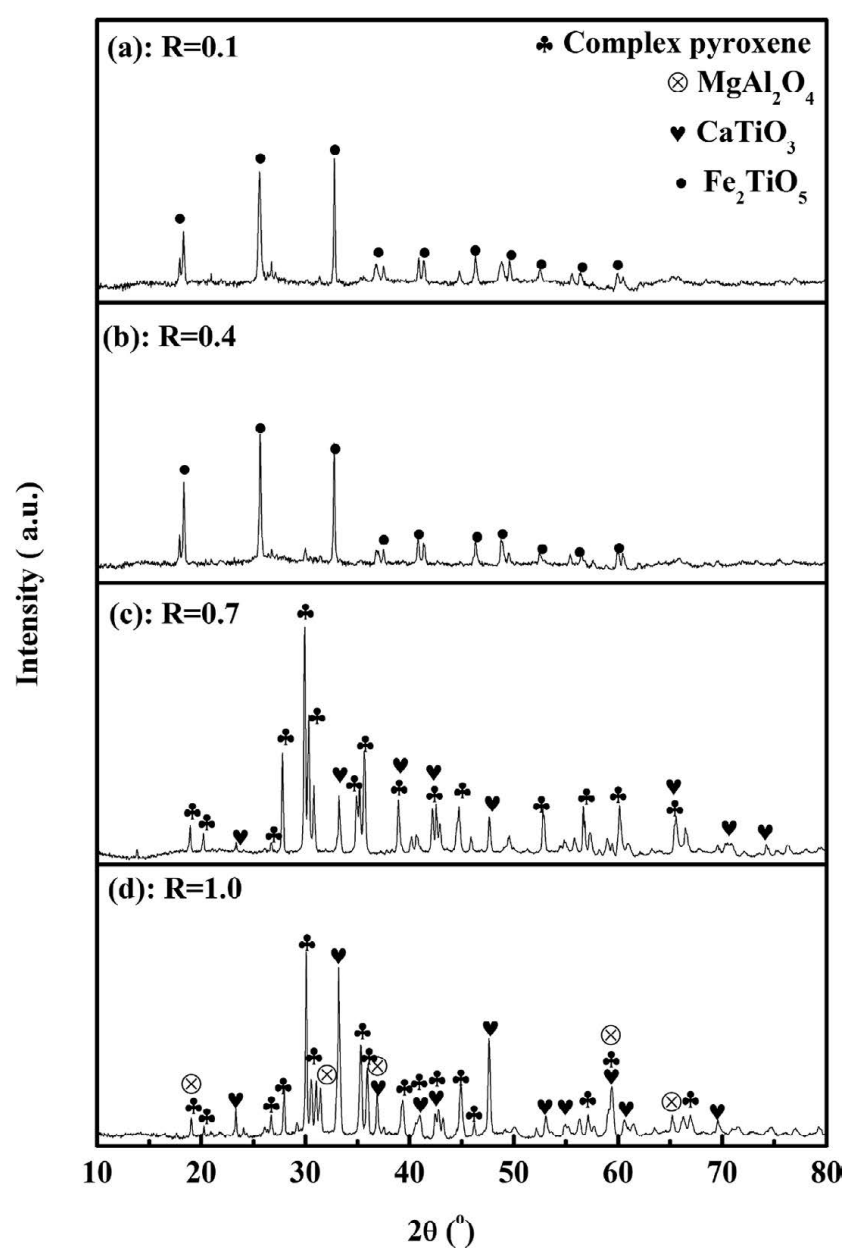

Fig. 8. XRD patterns of the slag phase after smelting-separation under different slag basicities.

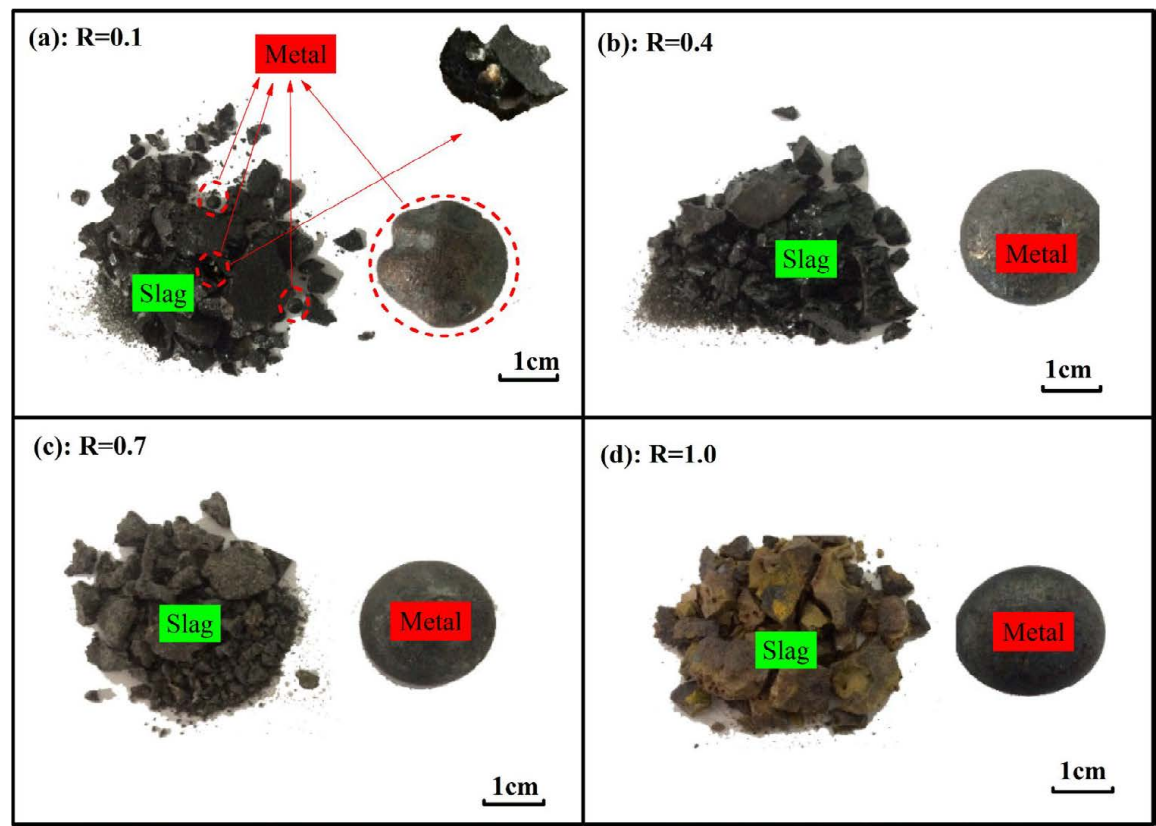

Fig. 7. Photographs of metal and slag phases after smelting-separation under different slag basicities. (Online version in color.) 


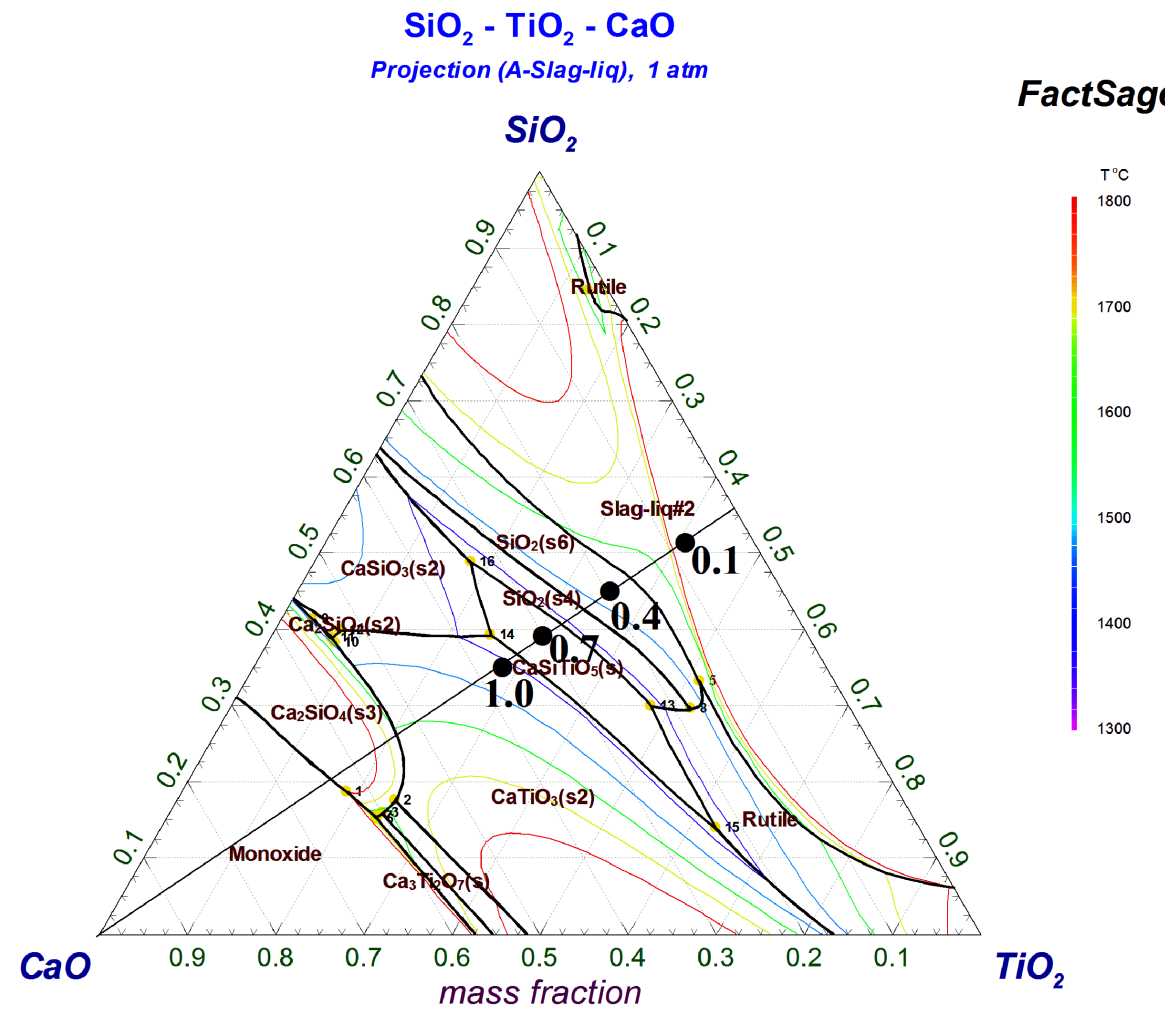

Fig. 9. Liquidus of $\mathrm{CaO}-\mathrm{SiO}_{2}-\mathrm{TiO}_{2}$ system. (Online version in color.)

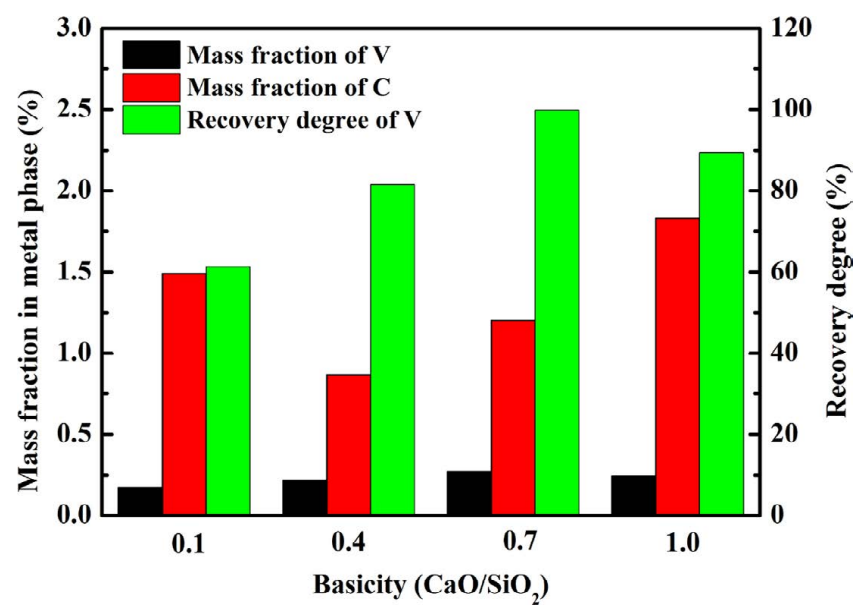

Fig. 10. Effect of slag basicity on the contents of $\mathrm{V}$ and $\mathrm{C}$ in metal phase and recovery degree of $\mathrm{V}$. (Online version in color.)

which will cause adverse effects on the smelting-separation of metallized pellets.

Figure 10 describes the variations of $\mathrm{V}$ and $\mathrm{C}$ contents in metal phase and recovery degree of $\mathrm{V}$ under different slag basicities. The mass fraction and recovery degree of $\mathrm{V}$ increase from $0.17 \%$ and $61.3 \%$ to $0.27 \%$ and $99.8 \%$, respectively, with the basicity increasing from 0.1 to 0.7 , and then decreases to $0.24 \%$ and $89 \%$ when the basicity is further increased to 1.0. It is indicated that the slag basicity has a significant impact on the recovery degree of $\mathrm{V}$, and when the basicity is 0.7 , the mass fraction and recovery degree of $\mathrm{V}$ reach the highest. It was well accepted that higher level of the slag basicity is benefit for the reduction of vanadium oxides within proper basicity range. To investigate the influences of slag basicity on the fluidity of molten

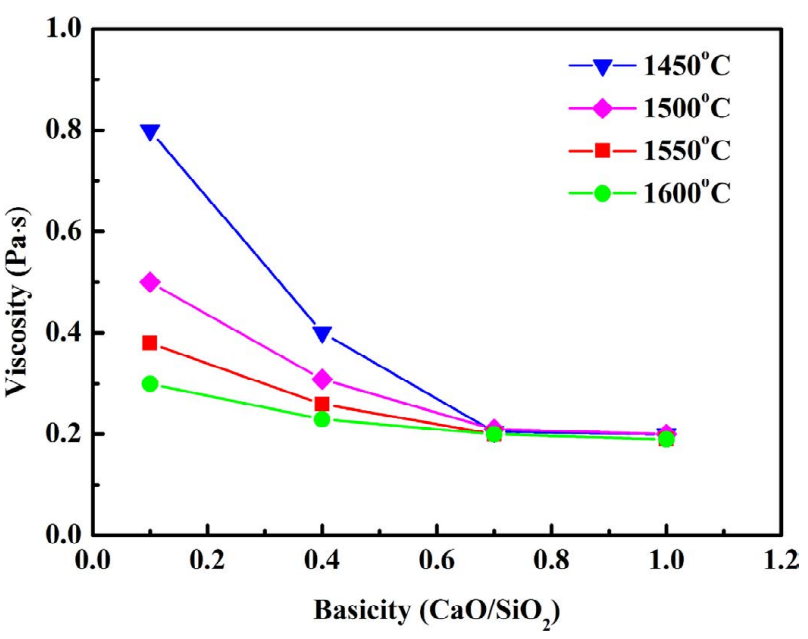

Fig. 11. Effect of slag basicity on the viscosity of molten slag. (Online version in color.)

slag, the viscosity of smelting-separation slag with different basicities was measured using a rotating viscometer (RTW10, China) by adjusting $\mathrm{CaO}$ contents. As shown in Fig. $\mathbf{1 1}$, the viscosity of molten slag obviously decreases as the basicity increases from 0.1 to 0.7 under temperature range of $1450-1600^{\circ} \mathrm{C}$, which improve the fluidity of molten slag and promote the mass transfer of $\mathrm{V}_{2} \mathrm{O}_{3}$ in the molten slag. Meanwhile, further increasing basicity from 0.7 to 1.0 did not have an obvious changes on the viscosity values, indicating that excessive high temperature has a weak improvement for the fluidity of molten slag in slag basicity range of $0.7-1.0$.

The impact of basicity on the properties of molten slag is attributed to the fact that a large amount of free oxygen ions $\mathrm{O}^{2-}$ are provided when the basicity is increased by 


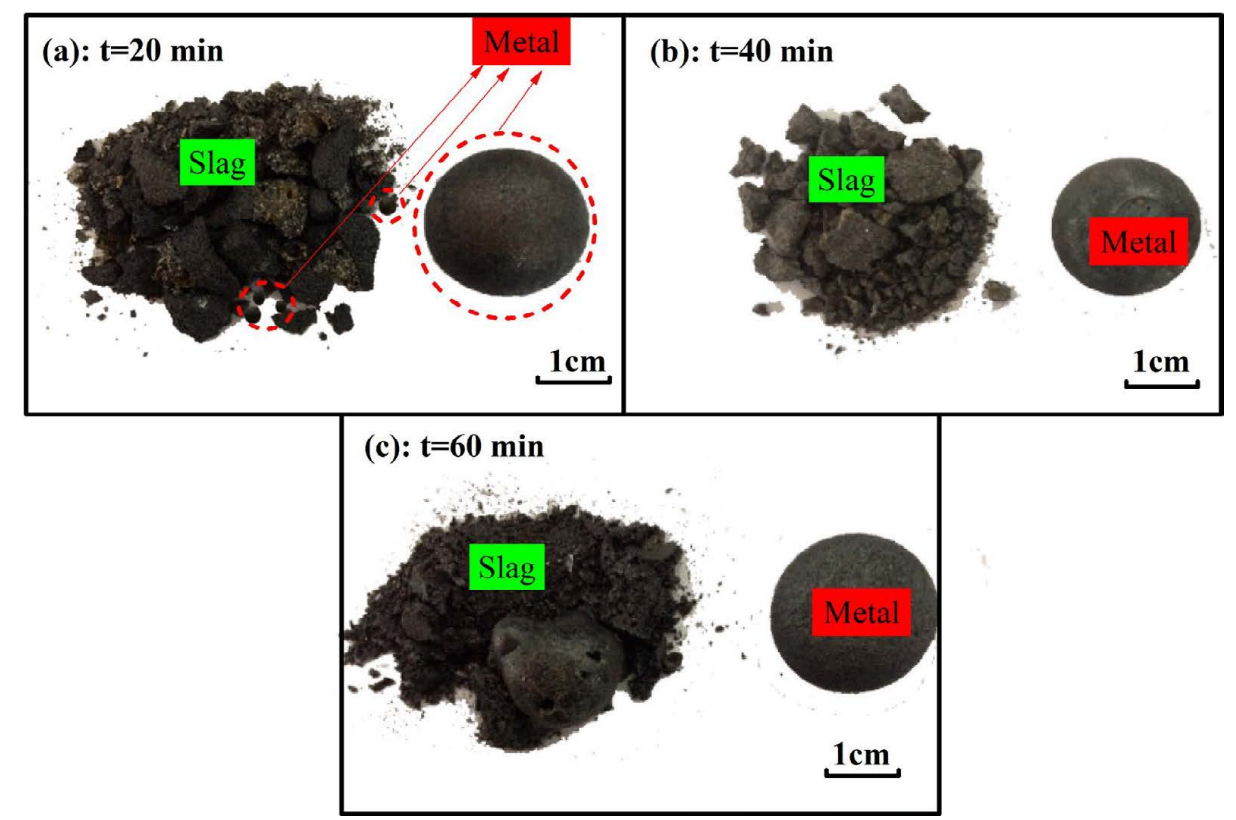

Fig. 12. Photographs of metal and slag phases after smelting-separation under different smelting times. (Online version in color.)

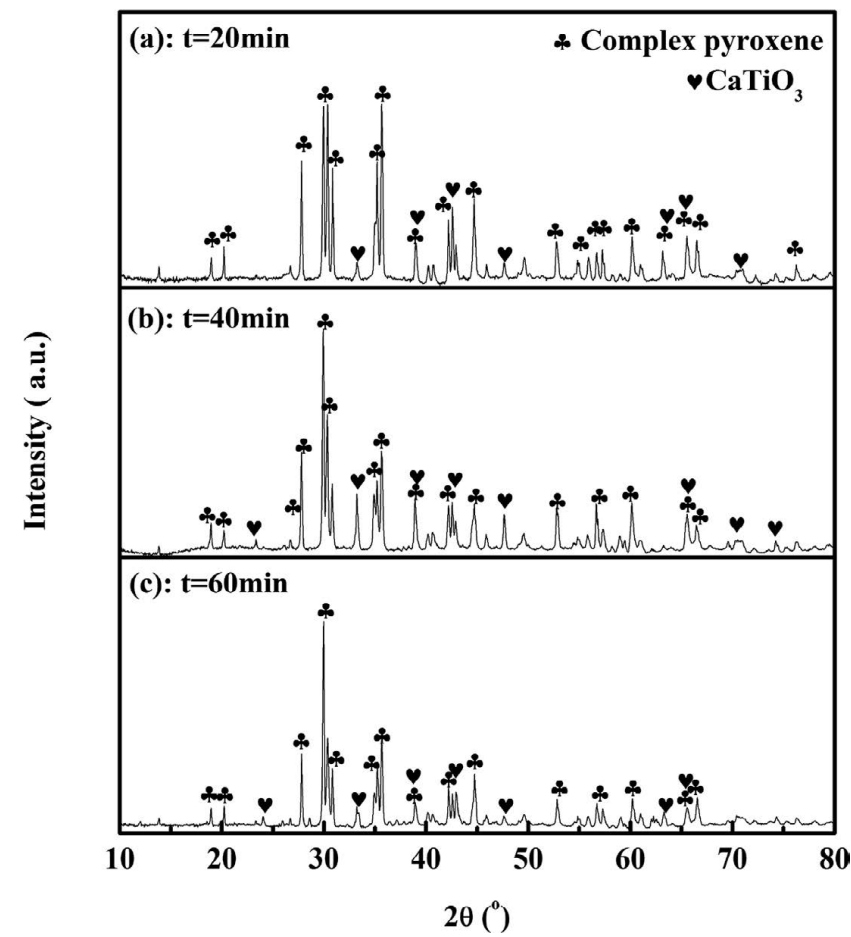

Fig. 13. XRD patterns of the slag phase after smelting-separation under different smelting times.

adding $\mathrm{CaO}$ oxides, which would destroy the complex network structure and decrease the polymerization degree of silicate. ${ }^{24)}$ Accordingly, the viscosity and liquidus temperature of molten slag are decreased. However, as the basicity is further increased to 1.0, the mass fraction and recovery degree of $\mathrm{V}$ appear a slight decreases. This is because that excessive $\mathrm{CaO}$ are combined with $\mathrm{TiO}_{2}$ to generate $\mathrm{CaTiO}_{3}$ with high-melting-point mineral, leading to an increase of liquidus temperature of molten slag and bad dynamic conditions for the mass transfer of $\mathrm{V}_{2} \mathrm{O}_{3}$ and $\mathrm{V}$. To obtain higher $\mathrm{V}$ recovery degree, the optimum slag basicity is about 0.7 .

The mass fraction of $\mathrm{C}$ initially decreases and subse- quently increases with the increment of slag basicity, showing an opposite tendency with that of $\mathrm{V}$. This may be related to the reduction of vanadium oxides by carbon. In fact, the iron carburization and reduction of vanadium oxides conduct simultaneously during smelting separation process. The accelerated reduction of vanadium oxides at the beginning consumes a large amount of carbon, resulting in a decrease of the carbon contents used for carburization. And then, as the mass fraction and recovery degree of $\mathrm{V}$ decreased, more carbons are used for carburization, increasing the carbon content in metal phase.

\subsection{Effect of Smelting Time}

The photographs of metal and slag phases after smeltingseparation under conditions of smelting temperature of $1450^{\circ} \mathrm{C}$ and slag basicity of 0.7 are presented in Fig. 12 . The metal phase can be well separated from slag phase under different smelting times. However, when the smelting time is $20 \mathrm{~min}$, a few small iron nuggets were found among the slag (Fig. 12(a)), indicating the incomplete coalescence and settlement of metallic iron droplets during smelting separation process due to the short smelting time. As the smelting time reached or exceeded $40 \mathrm{~min}$, the coalescence and settlement of the metallic iron droplets is improved and the iron nugget in slag vanishes (Figs. 12(b)-12(c)). Figure 13 displays the XRD patterns of smelting-separation slag obtained under different smelting times. The basic phase is complex pyroxene in the slag. Besides, it also contains a small amount of $\mathrm{CaTiO}_{3}$. It was found that there is no obvious change for slag phase as increasing the smelting time.

The effects of smelting time on the mass fractions of $\mathrm{V}$ and $\mathrm{C}$ in metal phase and recovery degree of $\mathrm{V}$ under different slag basicities are shown in Fig. 14. As smelting time increases from 20 to $40 \mathrm{~min}$, the mass fraction and recovery degree of $\mathrm{V}$ have a remarkable increases from $0.24 \%$ and $97 \%$ to $0.27 \%$ and $99.8 \%$, respectively. However, when smelting time is further extended to $60 \mathrm{~min}$, both the mass fraction and recovery degree of $\mathrm{V}$ appear a slight 


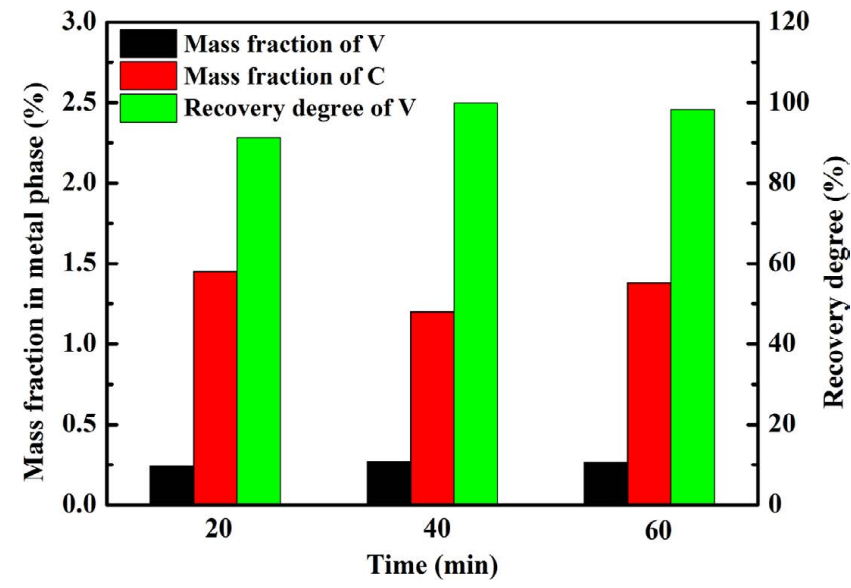

Fig. 14. Effect of smelting time on the contents of $\mathrm{V}$ and $\mathrm{C}$ in metal phase and recovery degree of $\mathrm{V}$. (Online version in color.)

decreases. It is supposed that reduction reaction is intense between 20 and $40 \mathrm{~min}$, and the concentration gradient in the diffusion region of molten slag is large. Meanwhile, in the smelting time of 40 to $60 \mathrm{~min}$, the reduction reaction of vanadium oxides have almost reached equilibrium, and the concentration difference in diffusion region and driving force of diffusion decrease. Accordingly, further increasing the smelting time has little impact on the reduction of vanadium oxides. In addition, excessive smelting time may lead to the reduction of titanium oxides and formation of $\mathrm{TiC}$ in slag, which would decrease the recovery of $\mathrm{TiO}_{2}$ in slag and deteriorate the kinetics of mass transfer of $\mathrm{V}_{2} \mathrm{O}_{3}$ in molten slag. ${ }^{25-27)}$ The carbon contents in metal phase exhibit the first decreasing and then increasing trend with the increase of smelting time. As described above, it is mainly related to the reduction of vanadium oxides during smelting separation of metallized pellets. On the one hand, both the coalescence and settlement of iron droplets and deep reductions of vanadium oxides in metallized pellets need take a certain times. On the other hand, excessive smelting time would consume large amounts of energy, which is unnecessary considering the decreased recovery degree of V. Therefore, the appropriate smelting time should be controlled to around $40 \mathrm{~min}$.

\subsection{Mass Balance of the Input and Output of the Ele- ments}

To fully understand what elements are going into the metal, vapor, and slag, an overall mass balance of the input and output of the elements was done under various experimental conditions, as shown in Tables 2-4. It can be seen that $99.86 \%$ of $\mathrm{V}$ in the metallized pellets can be reduced into metal phase under the optimized operation conditions, i.e., smelting temperature of $1450^{\circ} \mathrm{C}$, slag basicity of 0.7 and smelting time of $40 \mathrm{~min}$. The amounts of $\mathrm{V}$ in vapor and slag phases are so small that could be neglected. In addition, the carbon content dissolved into the metal phase accounts of $5-16 \%$ and most of carbon is used to reduce the iron, vanadium and manganese oxides.
Table 2. Mass balance of the input and output for $\mathrm{C}$ and $\mathrm{V}$ under different smelting temperatures.

\begin{tabular}{|c|c|c|c|c|c|c|}
\hline \multirow[b]{2}{*}{$\begin{array}{c}\text { Temperature } \\
\left({ }^{\circ} \mathrm{C}\right)\end{array}$} & \multirow[b]{2}{*}{ Element } & \multirow{2}{*}{$\begin{array}{c}\begin{array}{c}\text { Input } \\
\text { (gram) }\end{array} \\
\text { Pellet }\end{array}$} & \multicolumn{3}{|c|}{ Output (gram) } & \multirow{2}{*}{$\begin{array}{c}\text { Standard } \\
\text { deviations }\end{array}$} \\
\hline & & & Metal & Vapor & Slag & \\
\hline \multirow{2}{*}{1450} & $\mathrm{C}$ & 2.1030 & 0.3384 & 1.6403 & 0.0169 & \multirow{8}{*}{$\begin{array}{c}C: \pm 0.01 \% \\
V: \pm 0.05-0.5 \%\end{array}$} \\
\hline & V & 0.0504 & 0.0451 & $\approx 0$ & 0.0048 & \\
\hline \multirow{2}{*}{1500} & $\mathrm{C}$ & 1.2506 & 0.1155 & 1.0547 & 0.0144 & \\
\hline & V & 0.0300 & 0.0284 & $\approx 0$ & 0.0012 & \\
\hline \multirow{2}{*}{1550} & $\mathrm{C}$ & 1.7525 & 0.1234 & 1.5361 & 0.0122 & \\
\hline & V & 0.0420 & 0.0401 & $\approx 0$ & 0.0014 & \\
\hline \multirow{2}{*}{1600} & $\mathrm{C}$ & 2.1030 & 0.1096 & 1.7810 & 0.0134 & \\
\hline & V & 0.0504 & 0.0488 & $\approx 0$ & 0.0013 & \\
\hline
\end{tabular}

Table 3. Mass balance of the input and output for $\mathrm{C}$ and $\mathrm{V}$ under different slag basicities.

\begin{tabular}{|c|c|c|c|c|c|c|}
\hline \multirow[b]{2}{*}{ Basicity } & \multirow[b]{2}{*}{ Element } & \multirow{2}{*}{$\begin{array}{c}\begin{array}{c}\text { Input } \\
\text { (gram) }\end{array} \\
\text { Pellet }\end{array}$} & \multicolumn{3}{|c|}{ Output (gram) } & \multirow{2}{*}{$\begin{array}{c}\text { Standard } \\
\text { deviations }\end{array}$} \\
\hline & & & Metal & Vapor & Slag & \\
\hline \multirow{2}{*}{0.1} & $\mathrm{C}$ & 2.1030 & 0.2660 & 1.7356 & 0.0101 & \multirow{8}{*}{$\begin{array}{c}\mathrm{C}: \pm 0.01 \% \\
\mathrm{~V}: \pm 0.05-0.5 \%\end{array}$} \\
\hline & V & 0.0504 & 0.0309 & $\approx 0$ & 0.0170 & \\
\hline \multirow{2}{*}{0.4} & $\mathrm{C}$ & 2.103 & 0.1658 & 1.8821 & 0.0087 & \\
\hline & V & 0.0504 & 0.0411 & $\approx 0$ & 0.0084 & \\
\hline \multirow{2}{*}{0.7} & $\mathrm{C}$ & 2.1030 & 0.2240 & 1.6994 & 0.0059 & \\
\hline & V & 0.0504 & 0.0503 & $\approx 0$ & 0.00007 & \\
\hline \multirow{2}{*}{1.0} & $\mathrm{C}$ & 2.1030 & 0.3384 & 1.6403 & 0.0169 & \\
\hline & V & 0.0504 & 0.0451 & $\approx 0$ & 0.0048 & \\
\hline
\end{tabular}

Table 4. Mass balance of the input and output for $\mathrm{C}$ and $\mathrm{V}$ under different smelting times.

\begin{tabular}{|c|c|c|c|c|c|c|}
\hline \multirow[b]{2}{*}{$\begin{array}{l}\text { Time } \\
(\mathrm{min})\end{array}$} & \multirow[b]{2}{*}{ Element } & \multirow{2}{*}{$\begin{array}{c}\begin{array}{c}\text { Input } \\
\text { (gram) }\end{array} \\
\text { Pellet }\end{array}$} & \multicolumn{3}{|c|}{ Output (gram) } & \multirow{2}{*}{$\begin{array}{c}\text { Standard } \\
\text { deviations }\end{array}$} \\
\hline & & & Metal & Vapor & Slag & \\
\hline \multirow{2}{*}{20} & $\mathrm{C}$ & 2.1030 & 0.278 & 1.6796 & 0.0570 & \multirow{6}{*}{$\begin{array}{c}\mathrm{C}: \pm 0.01 \% \\
\mathrm{~V}: \pm 0.05-0.5 \%\end{array}$} \\
\hline & V & 0.0504 & 0.047 & $\approx 0$ & 0.0032 & \\
\hline \multirow{2}{*}{40} & $\mathrm{C}$ & 2.1030 & 0.224 & 1.6994 & 0.0059 & \\
\hline & V & 0.0504 & 0.0503 & $\approx 0$ & 0.00007 & \\
\hline \multirow{2}{*}{60} & $\mathrm{C}$ & 2.1030 & 0.256 & 1.6841 & 0.05320 & \\
\hline & V & 0.0504 & 0.0492 & $\approx 0$ & 0.0010 & \\
\hline
\end{tabular}

\section{Conclusions}

The slag-metal separation and reduction behaviors of vanadium-bearing titanomagnetite metallized pellets have been studied under different smelting temperatures, slag basicities and smelting times in the present work and the following main conclusions can be drawn from this study:

(1) Increasing smelting temperature would promote the reduction of vanadium oxides and decrease the viscosity of molten slag. Accordingly, an increase of the mass fraction 
in metal phase and recovery degree of $\mathrm{V}$ was obtained, whereas the mass fraction of $\mathrm{C}$ in metal phase decreases gradually. The smelting temperature is recommended to be maintained at about $1450^{\circ} \mathrm{C}$.

(2) Within slag basicity range of $0.1-0.7$, increasing slag basicity is conductive to the smelting-separation between slag and metal phases and decrease of slag viscosity, resulting in an increases of the mass fraction and recovery degree of V. However, further increasing slag basicity to 1.0 would cause abundant generation of perovskite with high melting point, which is bad for reduction of vanadium oxides and recovery degree of $\mathrm{V}$. The mass fraction of $\mathrm{C}$ initially decreases and subsequently increases, showing an opposite tendency with that of $\mathrm{V}$. Given the recovery index of $\mathrm{V}$, the proper slag basicity is about 0.7 .

(3) Appropriate extension of smelting time from 20 to 40 min contributes to the coalescence and settlement of iron droplets and fully reduction of vanadium oxides. When the smelting time is further increased from $40 \mathrm{~min}$ to $60 \mathrm{~min}$, the mass fraction and recovery degree of $\mathrm{V}$ appear slight decrease. The mass fraction of $\mathrm{C}$ increases firstly and then decreasing. The proper smelting time should be controlled to around $40 \mathrm{~min}$.

(4) Under the optimal conditions, smelting temperature of $1450^{\circ} \mathrm{C}$, slag basicity of 0.7 and smelting time of $40 \mathrm{~min}$, the recovery degree of $\mathrm{V}$ is $99.8 \%$, and the mass fractions of $\mathrm{V}$ and $\mathrm{C}$ in metal phase are $0.27 \%$ and $1.2 \%$, respectively.

\section{Acknowledgements}

The authors gratefully acknowledge the National Natural Science Foundation of China. [Grant numbers, 51774072, 51774073 and 51974080]

\section{REFERENCES}

1) E. Hukkanen and H. Walden: Int. J. Miner. Process., 15 (1985), 89.

2) T. Hu, X. Lv, C. Bai, Z. Lun and G. Qiu: Metall. Mater. Trans. B, 44 (2013), 252.

3) H. Sun, J. Wang, Y. Han, X. She and Q. Xue: Int. J. Miner. Process., 125 (2013), 122.

4) F. Zheng, F. Chen, Y. Guo, T. Jiang, A. Y. Travyanov and G. Qiu: JOM, 68 (2016), 1476.

5) L. Zhang, L. Zhang, M. Wang, G. Li and Z. Sui: Miner. Eng., 20 (2007), 684.

6) T. Hu, X. Lv, C. Bai, Z. Lun and G. Qiu: ISIJ Int., 53 (2013), 557.

7) S. Y. Chen and M. S. Chu: Int. J. Miner. Metall. Mater., 21 (2014), 225.

8) P. Taylor, S. Shuey, E. Vidal and J. Gomez: Min. Metall. Explor., 23 (2006), 80.

9) W. G. Fu, Y. C. Wen and H. E. Xie: J. Iron Steel Res. Int., 18 (2011), 7.

10) D. S. Chen, B. Song, L. N. Wang, T. Qi, Y. Wang and W. J. Wang: Miner. Eng., 24 (2011), 864.

11) P. Zheng: Non-Ferrous Min. Metall., 34 (2018), 35 (in Chinese).

12) L. S. Zhao, L. N. Wang, D. S. Chen, H. X. Zhao, Y. H. Liu and T. Qi: Trans. Nonferrous Met. Soc. China, 25 (2015), 1325.

13) S. Y. Chen and M. S. Chu: J. South. Afr. Inst. Min. Metall., 114 (2014), 481.

14) E. H. Wu, R. Zhu, S. L. Yang, L. Ma, J. Li and J. Hou: J. Iron Steel Res. Int., 23 (2016), 655.

15) J. Tang, M. S. Chu, C. Feng, Y. Tang and Z. Liu: ISIJ Int., 56 (2016), 210.

16) W. Li, G. Q. Fu, M. S. Chu and M. Y. Zhu: Steel Res. Int., 88 (2017), 1600228.

17) P. K. Iwamasa and R. J. Fruehan: ISIJ Int., 36 (1996), 1319.

18) J. J. Xin, L. Gan, L. N. Jiao and C. B. Lai: ISIJ Int., 57 (2017), 1340.

19) L. Gan, J. J. Xin and Y. H. Zhou: ISIJ Int., 57 (2017), 1303.

20) J. Qin: Iron Steel Vanadium Titan., 34 (2013), 13 (in Chinese).

21) A. Y. Ilyushechkin, M. Kochanek, L. G. Tang and S. Lim: Metall. Mater. Trans. B, 48 (2017), 1400.

22) G. Y. Zhang, C. Lei, Q. S. Zhu, J. B. Zhang, Z. Du, Y. F. Yang and C. L. Fan: Metall. Mater. Trans. B, 48 (2017), 302.

23) Y. R. Liu, J. L. Zhang, X. D. Xing, Z. J. Liu, X. L. Liu, N. Y. Li and Y. S. Shen: Metall. Mater. Trans. B, 48 (2017), 2419.

24) I. Sohn and D. J. Min: Steel Res. Int., 83 (2012), 611.

25) S. Wang, Y. Guo, T. Jiang, L. Yang, F. Chen, F. Zheng, X. Xie and M. Tang: JOM, 69 (2017), 1646.

26) C. Feng, M. S. Chu, J. Tang and Z. G. Liu: Int. J. Miner. Metall. Mater., 25 (2018), 609.

27) S. He, X. A. Fan, Q. M. Chang and L. X. Xiao: Metall. Mater. Trans. $B, 48$ (2017), 1748. 